\title{
Stunting spatial pattern in Rwanda: An examination of the demographic, socio-economic and environmental determinants
}

\author{
Vestine Uwiringiyimana, ${ }^{1,2}$ Antonie Veldkamp, ${ }^{1}$ Sherif Amer ${ }^{1}$ \\ ${ }^{1}$ Faculty of Geo-Information Science and Earth Observation (ITC), University of Twente, Enschede, \\ The Netherlands; ' ${ }^{2}$ Department of Food Science and Technology, College of Agriculture Animal Science \\ and Veterinary Medicine, University of Rwanda, Kigali, Rwanda
}

\begin{abstract}
Stunting is recognised as a major public health problem in Rwanda. We therefore aimed to study the demographic, socio-economic and environmental factors determining the spatial pattern of stunting. A cross-sectional study using the data from the 20142015 Rwanda Demographic and Health Survey and environmental
\end{abstract}

Correspondence: Vestine Uwiringiyimana, Faculty of Geo-Information Science and Earth Observation (ITC), University of Twente, Hengelosestraat 99 (359), 7514 AE Enschede, The Netherlands.

E-mail: v.uwiringiyimana@utwente.nl

Key words: Stunting; Environment; Height-for-age; Spatial pattern; Aflatoxin; Rwanda.

Acknowledgements: the authors thank the Demographic and Health Survey (DHS) Programme for granting them permission to use the Rwanda 2015 DHS data. The authors would like to also thank Mr. Marc Manyifika and Dr. Elias Nyandwi for their assistance in getting the spatial data used in the study.

Contributions: VU formulated the research question, designed the study, conducted the statistical analysis, interpreted the findings and wrote the manuscript. SA contributed to the interpretation of findings, the writing and critical revision of the manuscript; AV formulated the research question, designed the study, interpreted the findings, critically revised the manuscript. All authors read and approved the final version of the manuscript.

Conflict of interest: the authors declare no potential conflict of interest. Funding: this work was supported by the Nuffic funded NICHE/RWA/071 project.

Received for publication: 3 October 2019.

Revision received: 1 November 2019.

Accepted for publication: 1 November 2019.

${ }^{\mathbb{C} C}$ Copyright: the Author(s), 2019

Licensee PAGEPress, Italy

Geospatial Health 2019; 14:820

doi:10.4081/gh.2019.820

This article is distributed under the terms of the Creative Commons Attribution Noncommercial License (CC BY-NC 4.0) which permits any noncommercial use, distribution, and reproduction in any medium, provided the original author(s) and source are credited. data from external geospatial datasets were conducted. The study population was children less than two years old with their mothers. A multivariate linear regression model was used to estimate the effects of demographic, socio-economic and biophysical factors and a proxy measure of aflatoxins exposure on height-for-age. Also, a spatial prediction map of height-for-age to examine the stunting pattern was produced. It was found that age of child, height of mother, secondary education and higher, a child being male and birth weight were associated with height-for-age. After adjusting for demographic and socioeconomic factors, elevation and being served by a rural market were also significantly associated with low height-for-age in children. The spatial prediction map revealed the variability of height-for-age at the cluster-level that was lost when the levels are aggregated at the district level. No associations with height-for-age were found for exclusive breastfeeding, use of deworming tablets, improved water source and improved sanitation in the study population. In addition to the child and mother factors known to determine height-for-age, our study confirms the influence of environmental factors in determining the height-of-age of children in Rwanda. A consideration of the environmental drivers of anthropometric status is crucial to have a holistic approach to reduce stunting.

\section{Introduction}

Stunting among children remains a public health concern in Sub-Saharan Africa. Eastern and Central Africa have the highest stunting levels at $36.7 \%$ and $32.5 \%$, respectively (FAO et al., 2017). Stunting results in decreased motor and cognitive development, impaired immunity and low education attainment (Dewey and Begum, 2011). In adulthood, stunting leads to lower economic productivity, increased risk of chronic diseases and lower offspring birth weight (Victora et al., 2008). Stunting increases markedly in the first two years of life especially during the complementary feeding period (Black et al., 2008; Victora et al., 2010).

Stunting is the outcome of a complexity of factors. A prolonged lack of adequate and nutritious diet, coupled with recurring infections are direct causes of stunting. Child-related factors such as age, lower birth weight, lack of exclusive breastfeeding, and inadequate complementary feeding practices also increase the risk of stunting. Stunting is also influenced by maternal factors $(e . g$. short maternal stature, lower education, short birth spacing, poor health before conception), and by household and living characteristics (e.g. low income, inadequate water and sanitation and lower access to health services) (Stewart et al., 2013). The biophysical 
environment influences household food security and therefore directly or indirectly affects dietary diversity. Biophysical factors often studied include elevation, rainfall, temperature, relative humidity, topography, soil type, aridity, distance to urban areas and market access (de Sherbinin, 2011; Nikoi and Anthamatten, 2013).

Apart from nutrition, demographic, socio-economic and biophysical factors, mycotoxins exposure has also been linked to stunting. In many developing countries exposure to mycotoxins occurs via the food supply chain (Udomkun et al., 2017). Mycotoxins are toxic secondary metabolites produced by a group of fungal species that grow on cereals, nuts and legumes before or after harvest, especially under warm and humid conditions (Pitt, 2000; Cotty and Jaime-Garcia, 2007). Because many developing countries rely on subsistence farming and informal local markets, mycotoxins control is sometimes non-existent (Gbashi et al., 2018). Child exposure to mycotoxins, especially during the weaning period, is harmful as it impairs immunity and linear growth (Shephard, 2008; Khlangwiset et al., 2011; Vilcins et al., 2018). Among mycotoxins, exposure to aflatoxins and fumonisins has been consistently linked to stunting in children (Wild and Gong, 2010; Amuzie et al., 2016). Maize and peanut flours, often given to children as part of complementary feeding, are prime pathways for aflatoxins and fumonisins exposure (Udomkun et al., 2017).

In the past decade, Rwanda has made remarkable progress in improving food security (MINAGRI et al., 2016), access to health care (Lu et al., 2016), water and sanitation. This has led to reduced childhood undernutrition, especially wasting (NISR et al., 2015). In 2013, the country set a target of reducing child stunting to $24.5 \%$ by 2018 (MINALOC et al., 2014). Stunting however remains high with $38 \%$ of children under five being classified as stunted (NISR et al., 2015). It is estimated that Rwanda loses $11.5 \%$ of its gross domestic product due to child undernutrition (AUC and NEPAD, 2013). Recognising the complexity of stunting, Rwanda adopted a multi-sectoral approach focusing on early childhood development, improving water and sanitation as well as increasing social protection (MIGEPROF, 2018). On the other hand, the underlying factors leading to high levels of stunting in some regions in Rwanda remain unclear (MIGEPROF, 2018). Also, the contribution of mycotoxins exposure to the high levels of observed stunting in Rwanda remains a subject that is not well investigated. A lack of national level data on mycotoxins occurrence represents a serious challenge to mycotoxin research in Rwanda and in other developing countries (Gbashi et al., 2018).

To identify the local determinants of stunting, we conducted research in the northern region of Rwanda, which in 2010 was among the districts with the highest level of stunting (Uwiringiyimana et al., 2018). Follow-up research examined the impact of aflatoxin exposure on children's height-for-age, and established that exposure to aflatoxins via complementary flours was indeed associated with low child height-for-age (Uwiringiyimana, Ocke, Amer, Veldkamp, unpublished data). The analysis presented here takes a holistic approach as it not only considers the usual demographic and socio-economic factors known to influence stunting but also incorporates biophysical factors and exposure to mycotoxins.

Spatially explicit nationally representative data on mycotoxins in maize and peanut flours however do not exist in Rwanda. To overcome this lack of data, we developed a proxy for mycotoxin exposure which is based on the food supply chain of maize and peanut flours. Nationally, most households (70\%) get their complementary flours from markets (MINAGRI et al., 2016). In a local study conducted in the northern region of Rwanda (Uwiringiyimana, Ocke, Amer, Veldkamp, unpublished data), nearly all households surveyed (99\%) obtained their peanut flour from a market. Given that aflatoxin production will generally increase along the food supply chain and during storage (Hell and Mutegi, 2011), we hypothesised that household clusters that are supplied by markets located at the lower end of the food supply chain would stand an increased risk of mycotoxin exposure. The objectives of this study are threefold. First, to examine the demographic and socio-economic factors associated with the observed height-for-age variability in Rwanda. Second, controlling for the demographic and socio-economic factors, to identify the biophysical factors affecting height-for-age variability. Third, adjusting for the previous factors, to investigate if obtaining flour from the lower end of the food supply chain was associated with lower childhood height-for-age.

\section{Materials and Methods}

\section{Study area}

Rwanda is a country located in East-Africa with Tanzania to the East, Uganda to the North, Congo to the West and Burundi to the South. About $61.5 \%$ of Rwanda lies above 1,500 meters above the mean sea level, giving the country a temperate climate (Mendelsohn et al., 2016). Rwanda has four provinces, 30 districts, 416 sectors, 2,148 cells and 14,837 villages. The population is about 11 million, among which 1,5 million are under five (NISR and MINECOFIN, 2012). Figure 1 shows the spatial variability of stunting among the 30 districts of Rwanda. This study was based at the cluster level (containing between 100 and 300 households).

\section{Study sample}

The survey was conducted in a two-stage sample design based on demographic and socio-economic data from the 2014-15 collected from the Rwanda Demographic and Health Survey (DHS) (NISR et al., 2015). At the first stage, a total of 492 household clusters were selected within enumeration areas representing all 30 districts of Rwanda, 113 located in urban areas, and 379 in rural areas. For survey participation, 20 to 30 households were randomly selected from each cluster. The second stage involved systematic sampling of 26 households within each cluster, making up a sample of 12,792 households at the national level. From a subsample consisting of $50 \%$ of the households, indices of anthropometric status (child height and weight), individual mother and household characteristics were recorded for 3,813 children less than five years old. At the end of the survey, 1,467 children aged less than two years had valid height-for-age measurements, matched with their mothers' characteristics. All the demographic and socio-economic variables used were extracted from the 201415 DHS database for Rwanda, taking into account the survey weights, the variables definition and the denominators (Rutstein and Rojas, 2006).

\section{Demographic and socio-economic data}

The outcome variable was the height-for-age z-scores (HAZ) of children less than two years. Height-for-age is a measure of stunting or low height-for-age which indicates a prolonged nutrient deficit in children resulting in linear growth retardation (de Onis 
and Branca, 2016). A z-score less than -2 standard deviations (SDs) below the median of the World Health Organization (WHO) reference population (Onis, 2007) defines stunting. The independent demographic variables used were: i) age, sex, birth weight, exclusive breastfeeding, use of deworming tablets in the last six months, and the presence of diarrhoea in the two weeks preceding the survey for a child; ii) height, body mass index (BMI), highest education level, preceding birth interval (the difference in months between the current birth and the previous birth, counting twins as one birth), education level (no education, primary education, secondary education or higher) for a mother.

The socio-economic variables used were: i) type of residence, improved source of water, improved sanitation or toilet facility; ii) access to health care facility; iii) wealth index (a composite measure of a household's economic status, estimated from ownership of selected assets such as television, bicycles, type of residence including water access/sanitation facilities and access to health care facility; NISR et al., 2015).

\section{Environmental data}

The biophysical variables considered in the study were elevation, slope, temperature, rainfall and relative humidity. Table 1 displays the description of the environmental data. The elevation was produced from a digital elevation map (DEM) created by the Rwanda National Land Use and Development Master Plan Project through the Rwanda Natural Resources Authority. The slope was calculated from the DEM. The climatic factors temperature, rainfall, and relative humidity were measured from a network of 183 meteorological stations throughout Rwanda (Nyandwi et al., 2016). The annual average of these factors was measured for most stations using 60 years records starting from 1950 to 2010 by the Rwanda Meteorological Agency. After, the averages were interpolated for the whole country using thin-plate smoothing spline algorithm and saved as raster datasets with a $10-\mathrm{m}^{2}$ cell size (Nyandwi et al., 2016).

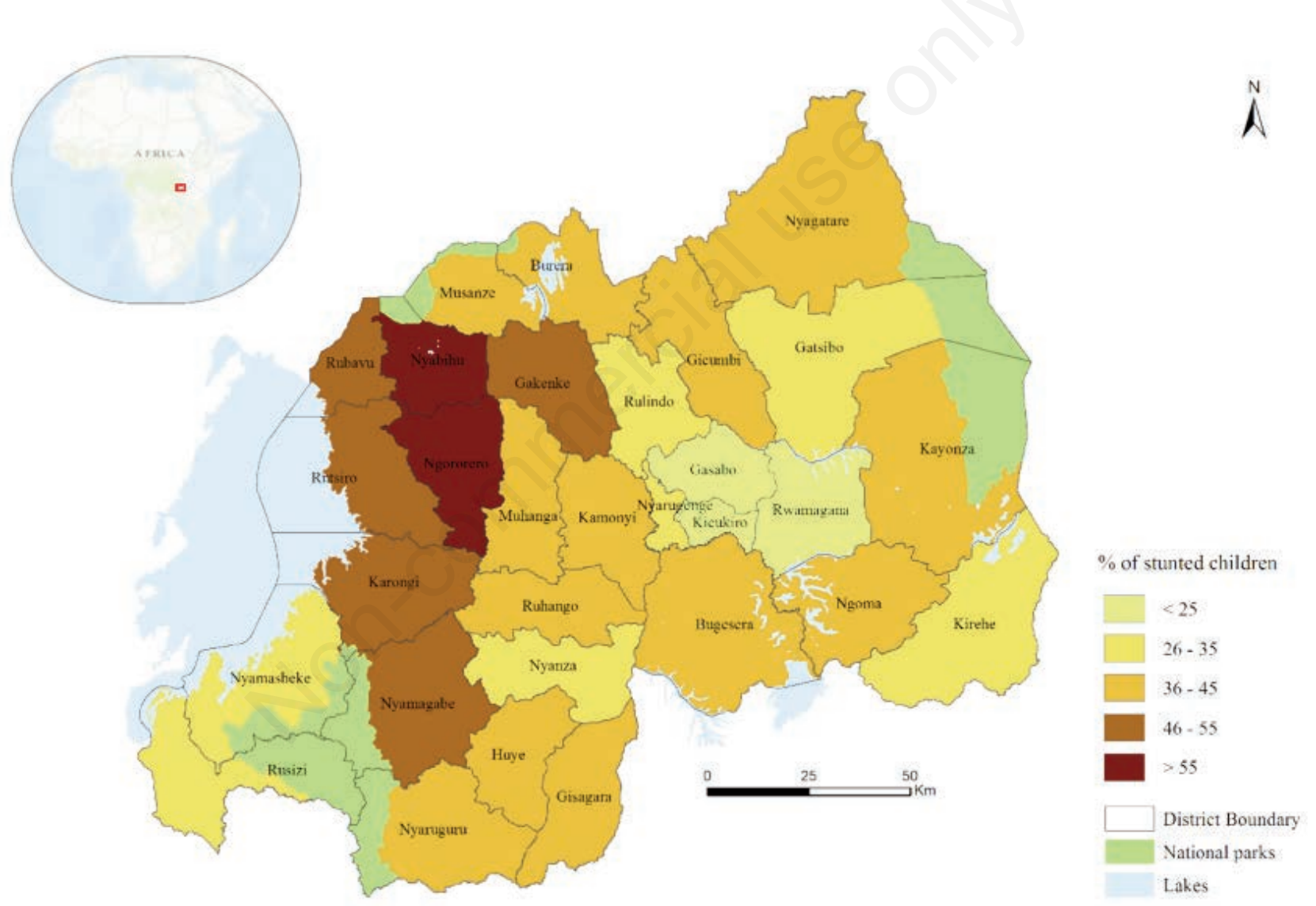

Figure 1. Stunting prevalence per district in Rwanda in 2015. Based on Demographic and Health Survey, 2015 (Rwanda location in Africa shown besides).

Table 1. Description of environmental variables.

\begin{tabular}{|c|c|c|}
\hline Data type & Variable & Description \\
\hline Topographic & Elevation and slope & $\begin{array}{l}\text { Created from a DEM and further used to generate the slope } \\
\text { using ArcGIS. Both raster files were created at a cell size of } 10 \mathrm{~m}^{2}\end{array}$ \\
\hline Climatic & Temperature, rainfall, and relative humidity & $\begin{array}{l}\text { Annual means from meteorological weather stations, } \\
\text { interpolated and resampled to a cell size of } 10 \mathrm{~m}^{2}\end{array}$ \\
\hline
\end{tabular}




\section{Merging environmental data and Demographic and Health Survey data}

To merge the environmental data with DHS data, each biophysical factor was extracted per household cluster using zonal statistics in ArcGIS Desktop, release 10.4 (ESRI, Redlands, CA, USA). Consideration was made, however, by taking into account the geographical displacement of the cluster done by DHS for every household survey (Burgert et al., 2013). For protecting the confidentiality of survey participants, DHS displaces the global positioning system (GPS) coordinates of urban clusters up to two $\mathrm{km}$, and of rural clusters up to $5 \mathrm{~km}$. Thus, before extracting the biophysical factors per cluster, we created a buffer of $5 \mathrm{~km}$ around all rural clusters and a buffer of $2 \mathrm{~km}$ around all urban clusters. The mean value of each environmental variable was extracted using the zonal statistics tool in ArcGIS.

\section{Classification of household clusters}

As the environmental conditions in the tropics are known to be very conducive to the production of mycotoxins (Gbashi et al., 2018), and given that aflatoxin contamination increases along the food supply chain due to poor post-harvest management (Kamika et al., 2016), we considered household clusters that would obtain their flour from markets at the lower end of the food supply chain as being at risk of exposure to higher aflatoxin levels from complementary flour compared to household clusters that obtain their flour at the start of the food supply chain. Because the food supply chain is a hierarchy from main markets to regional and local markets, we classified the clusters as follows: household clusters served by an urban market were considered as obtaining their flour from markets at the top of the food supply chain (least risk of aflatoxin exposure), while clusters exclusively served by a rural market were considered as obtaining their flour from markets at the intermediate level (increased risk of exposure) and clusters obtaining flour from local shops at the end of the food supply chain (highest risk of exposure). Based on this situation, the road network of Rwanda, the market locations and the boundaries of urban areas were used to classify the clusters into data layers.

The national road network, produced by the Rwanda Land
Management and Use Authority (RLMUA) within the land cadastral project in 2009-2010 categorises roads into national, district and other roads. The existing boundary of urban areas in Rwanda was also delineated by RLMUA during its land demarcation project for the production of urban master plans of Rwandan districts. The market location was produced by the National Institute of Statistics of Rwanda (NISR) by collecting information on the location of each market on the ground. A summary of the process followed to compute the distance variables is shown in Figure 2. We computed the distance from each household cluster to the closest urban or rural market in ArcGIS.

To prepare the data for network analysis, a road layer was first built followed by a market layer with the existing boundary of urban areas. The markets were extracted and categorised as urban or rural taking into account that main markets in urban areas supplying flour to rural markets. Then, two distance variables were calculated from each household cluster to the closest urban and rural markets using the network analyst tool.

Because of the geographic displacement of the household clusters done by DHS to protect the confidentiality of survey respondents, using a continuous distance variable from a household cluster to any closest facility could introduce a bias in the measurements computed. To reduce this bias, categorising the distance according Burgert et al. (2013) we used two categories for distance to market ( 5 and $10 \mathrm{~km}$ ). These two cut-offs were chosen to consider the walkable distance from a household cluster to the closest market, and also because they take into account the geographical displacement of both the urban and the rural household clusters. The distance variables were used to classify the household clusters into the three categories depending on where they would obtain their flour, all within a 5 or $10 \mathrm{~km}$ radius: i) household clusters served by an urban market; ii) household clusters exclusively served by a rural market; and iii) household clusters neither served by an urban market nor a rural one.

\section{Statistical analysis}

All variables were imported into SPSS Statistics for Windows, version 24.0 (IBM Corp., Armonk, NY, USA) for statistical analy-

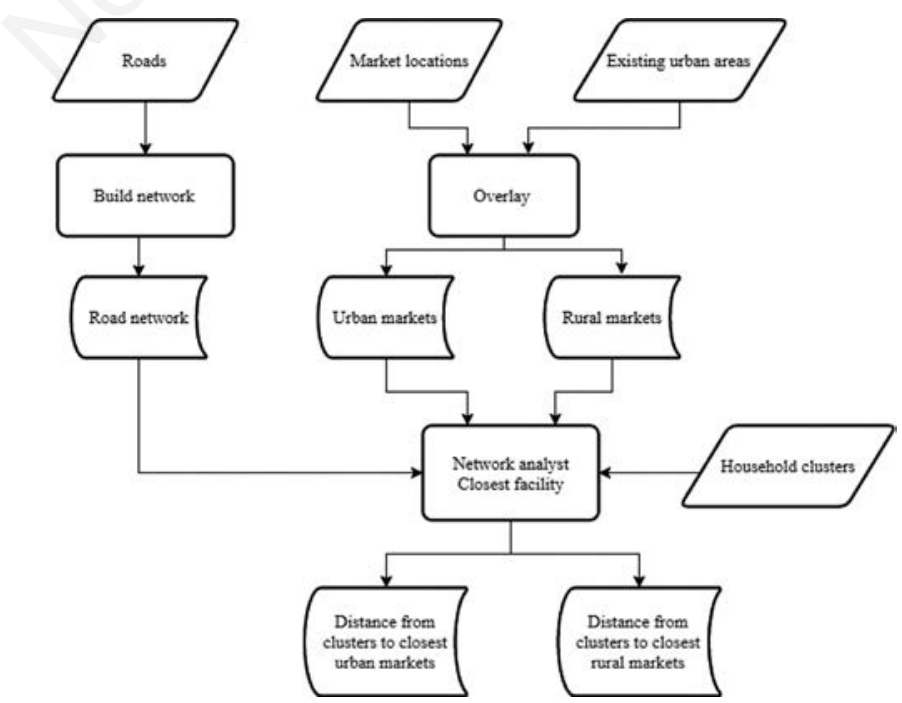

Figure 2. Flowchart explaining the calculation of distance to markets. 
sis. Descriptive statistics were run on all variables. Mean, median and SD were reported for continuous variables. Percentages were displayed for discrete ones. Maps of the independent variables aggregated per household cluster were produced to visualise their spatial pattern. For the spatial pattern of categorical variables, the percentage levels were displayed. For continuous variables, such as mothers BMIs, classes of BMI indicating underweight, normal weight, overweight and obesity, were used to visualise the spatial pattern. Correlation between the anthropometric status and the independent variables were ran on all variables to study the linear relationship with height-for-age. A hierarchical stepwise linear regression model was applied to determine the factors that were significant HAZ determinants. Three hierarchical stepwise models were run, with demographic and socio-economic factors that affect height-for-age entered first. The second block consisted of environmental variables and in the third block, the household clusters classification variables, based on the type of market that served each cluster. The independent variables retained in the final model were all significant at the $\mathrm{P} \leq 0.05$ level. Given that most regression analyses have been criticised of overlooking or not correcting for the spatial dependence which biases the results of the regression models (Voss et al., 2006; de Sherbinin, 2011), we checked for possible spatial autocorrelation in our analyses. Thus, the results of the final model were validated by visualising the pattern of the residuals in ArcGIS, and running a spatial autocorrelation analysis using Global Moran's $I$ to assess the non-spatial clustering of the model residuals. Spatial autocorrelation indicates that the errors in the model are not independent (Voss et al., 2006). When spatial autocorrelation is present, it reduces the standard errors of the estimates, increases the $t$-values and reduces the P-value thereby leading to a bias in the model (Voss et al., 2006). Moran's $I$ is similar to Pearson's correlation coefficient, and has values ranging from 1 to 1 , with positive values indicating high values surrounded by high values and, negative results showing spatial randomness. A prediction map based on the model predicted height-for-age zscores per household cluster and per district was produced using natural breaks.

\section{Results}

The descriptive characteristics of the study population is presented in Table 2, while Figure 3 displays the spatial variability existing within the demographic and socio-economic variables per cluster. The high percentage of stunting is more common in the North, West and south-eastern part of Rwanda and varies from $0 \%$
A

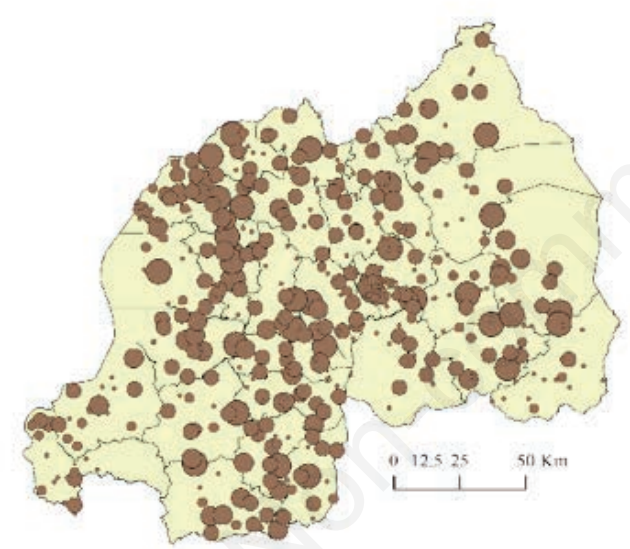

C

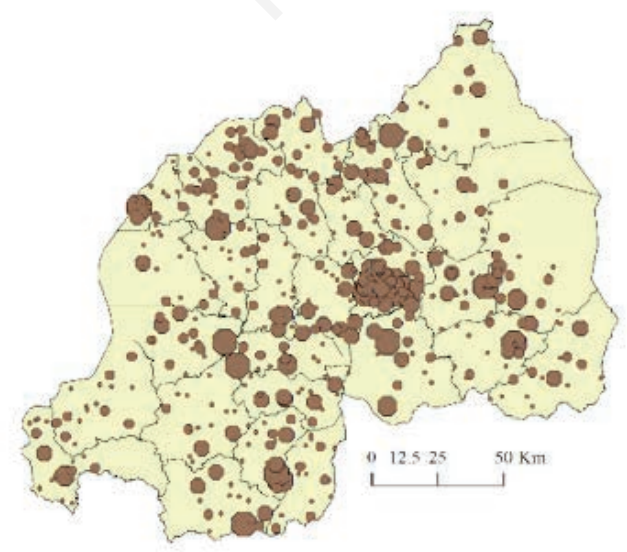

B
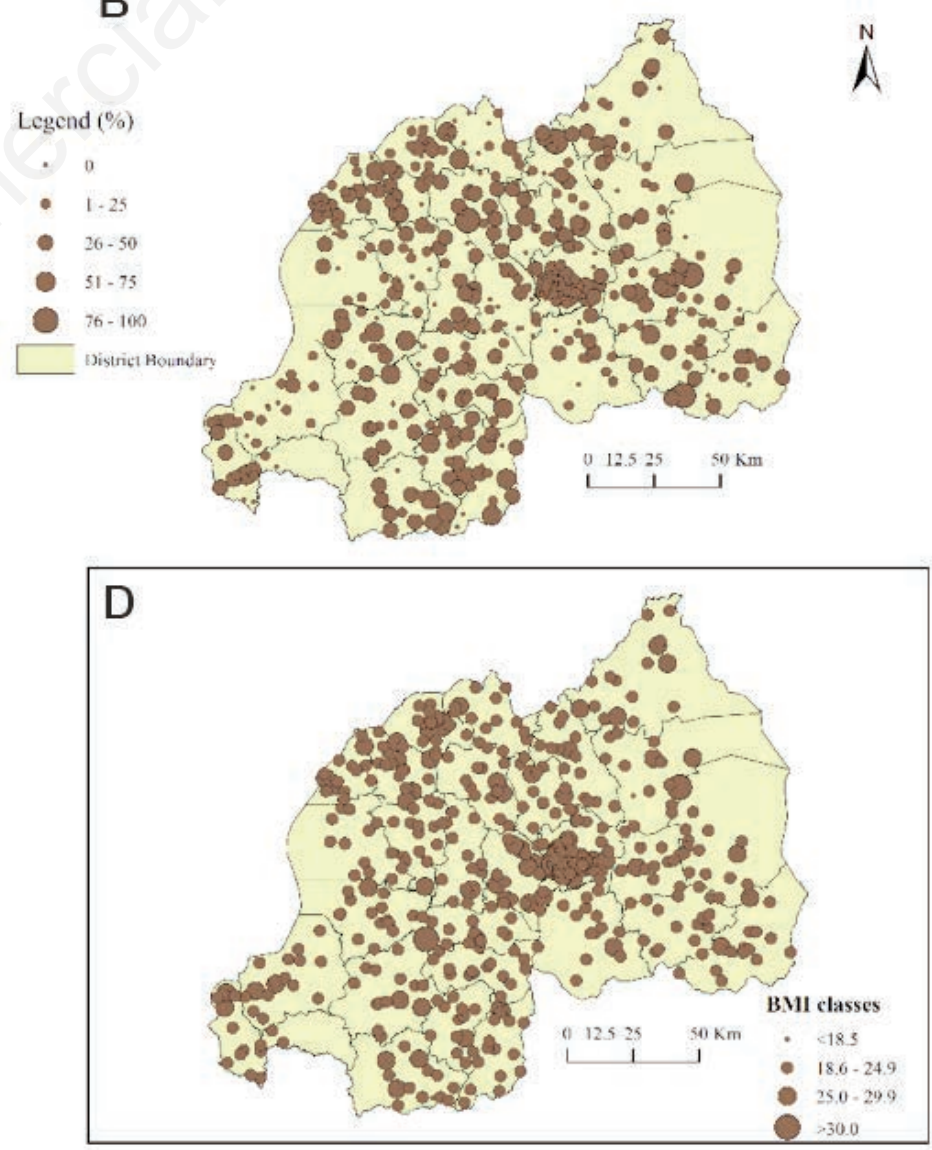

Figure 3. Prevalence rate of Demographic and Health Survey variables per cluster. A) Prevalence rate of stunting; B) percentage of exclusive breastfeeding; C) secondary and other higher education of mother; D) mothers' body mass index (BMI) classes per cluster. 
to $100 \%$ in some clusters (Figure 3A). Exclusive breastfeeding of children less than six months was generally below $75 \%$ (Figure 3B). As expected, mothers with secondary education and higher mostly lived in Kigali (Figure 3C). On the other hand, the BMI of mothers were uniformly spread across the country (Figure 3D).

As shown in Figure 4, the percentage of children receiving deworming tablets in the last six months (Figure 4A) was higher across the country as opposed to the prevalence of diarrhoea (Figure 4B). The use of non-improved water source (Figure 4C) in the households was more pronounced in the East, North and some regions in the South. On the other hand, the use of non-improved sanitation (Figure 4D) was evenly spread across the four provinces of Rwanda.

Table 3 shows the results from the household cluster classification. Household clusters that were served by an urban market within a 5 and a $10-\mathrm{km}$ radius were $21 \%$ and $32 \%$, respectively. Household clusters served only by a rural market were $39 \%$ and $61 \%$ within the 5 and $10 \mathrm{~km}$, respectively. Household clusters served by neither an urban nor a rural market within $5 \mathrm{~km}$ were $40 \%$ as opposed to $7 \%$ within $10 \mathrm{~km}$.

Figure 5 shows the spatial distribution of the household clusters as served by an urban market or a rural market within a $5 \mathrm{~km}$ (Figure 5A) and $10 \mathrm{~km}$ radius (Figure $5 \mathrm{~B}$ ). The majority of household clusters that were served by a market at the top of the food supply chain were located in urban areas. According to our assumption of increased aflatoxin contamination along the food supply chain, these household clusters were considered as clusters with the least risk of exposure to higher aflatoxin level. Household clusters served by markets at the intermediate level in the food supply chain were mostly located in rural areas; and thus they will be more exposed to aflatoxins compared to clusters located in the urban areas, assuming the rural markets get their supply from the urban markets. Finally, the household clusters neither served by an urban nor a rural market within a $10-\mathrm{km}$ radius, which is the third category, will be potentially the most exposed to higher levels of aflatoxins.

As can be seen in Table 4 showing the results of the hierarchical linear regression model, the child's age, mother's height, secondary education, being male, birth weight was significantly associated with height-for-age. From the biophysical factors, elevation was a significant predictor of height-for-age in children. Being served by a rural market within $10 \mathrm{~km}$ radius was negatively associated with the height-for-age in children. The HAZ significantly decreased as a cluster changed from being served by an urban market to being served by a rural market within a $10-\mathrm{km}$ radius. The adjusted $\mathrm{R}^{2}$ of the final model was 0.27 , implying that $27 \%$ of the total variability in stunting can be explained by this significant empirical model.

Figure 6 shows the results of the spatial autocorrelation analysis with residuals on the $\mathrm{x}$-axis and the lagged residuals on the $\mathrm{y}$ axis. The lagged residuals represent the sum of weighted residuals of neighbouring household clusters indicating that there is no spatial autocorrelation among residuals, thereby confirming their independence. Figure 7B shows the spatial pattern of the predicted values of HAZ at the cluster-level in Rwanda, based on the model presented in Table 4, with the same mean HAZ aggregated to the district level. Overall, the central region of Rwanda has normal height-for-age values in contrast to the northern and the western regions that have mostly low height-for-age values. The aggregation to the district level, however, overshadows the clusters with higher HAZ, which are surrounded by clusters with lower HAZ.
As seen in Figure 7A, the same is observed from the comparison with the commonly reported stunting prevalence per district. Compared with Figure 1, the spatial variability in HAZ is lost due to data aggregation at the district levels.

Table 2. Descriptive statistics of dependent and independent variables used in the study.

\begin{tabular}{|c|c|c|c|c|}
\hline Variable & Mean & SD & No. of clusters & $\%$ \\
\hline \multicolumn{5}{|l|}{ Continuous } \\
\hline Height-for-age & -1.2 & 1.5 & 1,467 & \\
\hline Child age (months) & 11 & 7.0 & 1,514 & \\
\hline Child birth weight (kg) & 3.3 & 0.6 & 1,509 & \\
\hline Mother's BMI $\left(\mathrm{kg} / \mathrm{m}^{2}\right)$ & 23.1 & 3.5 & 1,509 & \\
\hline Mother's height (cm) & 156.9 & 6.1 & 1,509 & \\
\hline Birth index (months) & 11.4 & 6.6 & 3,122 & \\
\hline Wealth index & -0.1 & 0.8 & 3,122 & \\
\hline Elevation (m) & 1702 & 348.0 & & \\
\hline Slope (degrees) & 11.7 & 10.9 & & \\
\hline Rainfall (mm) & 1208 & 259.0 & & \\
\hline Relative humidity & 73.9 & 3.6 & & \\
\hline \multicolumn{5}{|l|}{ Categorical } \\
\hline \multicolumn{3}{|l|}{ Stunting } & 1,467 & 30.2 \\
\hline \multicolumn{3}{|l|}{$\begin{array}{l}\text { Sex } \\
\quad \text { Female } \\
\text { Male }\end{array}$} & 3,122 & $\begin{array}{l}50.1 \\
49.9\end{array}$ \\
\hline \multicolumn{3}{|l|}{ Exclusive breastfeeding } & 2,972 & \\
\hline \multicolumn{3}{|l|}{ Yes } & & 25.3 \\
\hline $\begin{array}{l}\text { Mother's education } \\
\text { No education } \\
\text { Primary education } \\
\text { Secondary education } \\
\text { Higher }\end{array}$ & & & 3,122 & $\begin{array}{l}13.3 \\
71.8 \\
12.5 \\
2.4 \\
\end{array}$ \\
\hline \multicolumn{3}{|l|}{$\begin{array}{l}\text { Improved water source* } \\
\text { Yes }\end{array}$} & 3,074 & 72.5 \\
\hline \multicolumn{3}{|l|}{$\begin{array}{l}\text { Improved sanitation }{ }^{\circ} \\
\text { Yes }\end{array}$} & 3,074 & 70.2 \\
\hline \multicolumn{4}{|c|}{$\begin{array}{l}\text { Deworming tablets use in last six months } \\
\text { Yes }\end{array}$} & $\begin{array}{c}3,116 \\
48.6\end{array}$ \\
\hline \multicolumn{3}{|c|}{$\begin{array}{l}\text { Diarrhoea in last two weeks } \\
\text { Yes }\end{array}$} & 3,122 & 17.0 \\
\hline
\end{tabular}

Data source: Demographic and Health Survey, Rwanda 2014-2015 and authors' own calculations. SD, standard deviation; BMI, body mass index * *includes piped water, public tap/standpipe, tube well, borehole, protected well, protected spring, rainwater; ${ }^{\circ}$ includes connection to a piped sewer system, to a septic tank, to a pit latrine, ventilated improved pit latrine, pit latrine with slab, composting toilet. Shared improved facilities are also included.

Table 3. Household clusters classification.

\begin{tabular}{lcc} 
Variable & $\begin{array}{c}\text { Sample sive (\%) } \\
5 \mathrm{~km}\end{array}$ & $10 \mathrm{~km}$ \\
\hline Distance categories & & \\
Household clusters served by an urban market & $106(21)$ & $158(32)$ \\
Household clusters exclusively served by a rural market & $90(39)$ & $300(61)$ \\
\hline Household clusters served by neither an urban nor a rural market & $196(40)$ & $34(7)$ \\
\hline
\end{tabular}




\section{Discussion}

We studied the determinants of the spatial pattern of heightfor-age at the household cluster level in Rwanda considering demographic, socio-economic variables and environmental variables, with a proxy variable for aflatoxin exposure in children. Stunting prevalence in children in Rwanda was 30.2\% which, according to the present stunting prevalence thresholds (de Onis et $a l ., 2019)$, is considered very high. Factors associated with stunting were the child's age, the mother's height, the mother's education, the child's gender and its birth weight. The direction of the relationship for each covariate was as expected. First, the age of children was negatively associated with height-for-age, a result that aligns with other studies in the sense that as a child becomes older, the risk of stunting increases (Dewey and Huffman, 2009). Second, the mother's height was positively associated with the
A

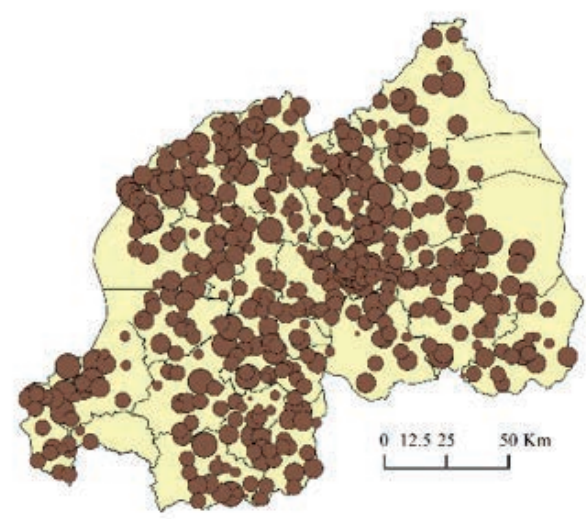

C

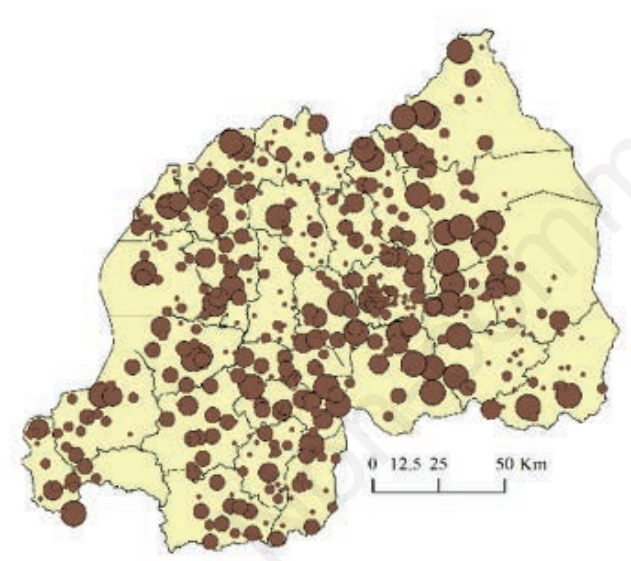

B
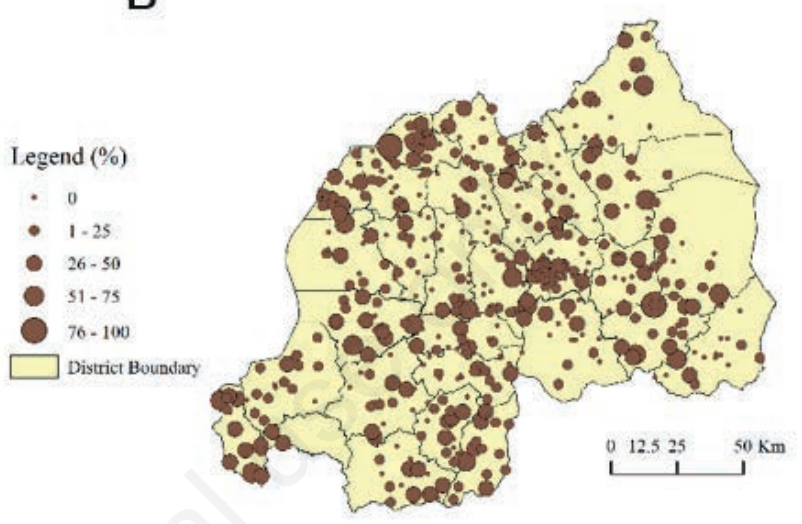

D

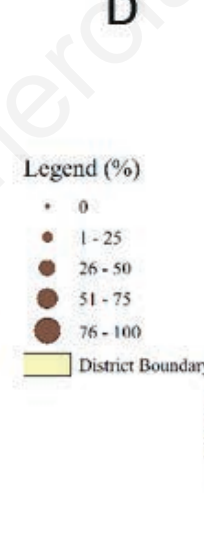

$\bigwedge^{N}$

Figure 4. Prevalence rate of Demographic and Health Survey variables per cluster. A) Prevalence rate of using deworming tablets in last six months; B) percentage of diarrhoea in last two weeks; C) non-improved water source in the households; D) non-improved sanitation in household.

Table 4. Regression coefficients of the socio-economic, environmental and accessibility factors on height-for-age.

\begin{tabular}{|c|c|c|c|c|}
\hline \multirow[t]{2}{*}{ Variables } & \multicolumn{2}{|c|}{ Non-standardized coefficients } & \multirow{2}{*}{$\begin{array}{c}\text { Standardized coefficients } \\
\text { Beta }\end{array}$} & \multirow{2}{*}{$\begin{array}{c}95 \% \text { CI } \\
\text { Lower, Upper }\end{array}$} \\
\hline & B & Standard error & & \\
\hline Child's age (months) & $-0.08 * *$ & 0.01 & -0.328 & $-0.102,-0.062$ \\
\hline Mother's height $(\mathrm{cm})$ & $0.06^{* *}$ & 0.01 & 0.223 & $0.036,0.078$ \\
\hline Secondary education or higher & $0.01 *$ & 0.00 & 0.128 & $0.002,0.010$ \\
\hline Child being male & $-0.01^{*}$ & 0.00 & -0.132 & $-0.010,-0.002$ \\
\hline Child's birth weight (kg) & $0.32 *$ & 0.13 & 0.102 & $0.065,0.583$ \\
\hline Elevation (m) & $-0.00^{* *}$ & 0.00 & -0.207 & $-0.001,0.000$ \\
\hline Cluster served by an urban $v$ s a rural market & $-0.18^{*}$ & 0.09 & -0.086 & $-0.351,-0.007$ \\
\hline
\end{tabular}

B, Non-standardized coefficient; Beta, Standardized coefficient; CI, Confidence interval. ${ }^{*} \mathrm{P} \leq 0.05,{ }^{*} \mathrm{P} \leq 0.001$. Adjusted $\mathrm{R}^{2}$ of the model is 0.27 . 
height-for-age of her child, showing the relation between maternal nutrition and anthropometric status of the child. Maternal short stature is a high-risk factor of intra-uterine growth restriction, which has previously been linked to childhood stunting (Black et al., 2013). Third, we found that secondary education or higher of the mother was positively associated with height-for-age. In Uganda, Wamani et al. (2007) found similar results. Chopra (2003) and Sakisaka et al. (2006) also identified that low maternal education was associated with lower height-for-age of children.

In our study, a child being male was negatively associated with height-for-age. Previous Rwandan DHS surveys (INSR and Macro, 2006; NISR et al., 2010) have shown a similar pattern. The Rwanda DHS of 2010 showed that $47.4 \%$ of the boys were stunted compared to $41.4 \%$ of the girls. The Rwanda DHS of 2005 identified that $46.3 \%$ of the boys were stunted compared to $44.4 \%$ of the girls. In a study on sex differences in the nutritional status of HIVexposed children in Rwanda, Condo et al. (2015) found significant differences in stunting status, with male children being more stunted than their female counterparts, although they did not find a significant difference in feeding practices between male and female children. As for birth weight, our findings showed that higher birth weight was positively associated with height-for-age. Black et al. (2013) have shown that children with normal birth weight are more protected against infections and have less mortality risk compared to children with a low birth weight.

Although exclusive breastfeeding, use of deworming tablets, access to improved water source and sanitation of the household are known to influence height-for-age (Stewart et al., 2013), our multi-variate analysis did not identify any significant association. Preceding birth interval, mothers' BMI, and type of residence were also not significantly associated with stunting. Households living in areas of higher altitude negatively associated with the heightfor-age of children. The robustness of the elevation covariate was consistent throughout the analysis. Similarly, Dang et al. (2004) found that children living in mountainous regions have a higher risk of becoming stunted than children brought up in lowlands. Elevation could have a direct effect on height-for-age, but it is more probable that these are more remote areas with higher food insecurity and lower levels of access to health care services. In a comprehensive vulnerability survey conducted in Rwanda in 2015, households at high altitudes were more at risk due to food insecurity, and their children were also found to be more stunted compared to those living in the rest of the country (MINAGRI et al., 2016). On the other hand, in this study we tested the accessibility to health care services, and did not find a significant relationship between distance to health facilities and height-for-age. This is probably because the health care services delivery in Rwanda is well organised with a universal health care system and thus equally accessible to the majority of the population (Binagwaho et al., 2014). We tested other environmental factors such as rainfall, relative humidity and slope. These covariates were not statistically significant. However, this non-significant result might result from the cross-sectional nature of our study. Considering seasonality in future studies might reveal an impact of these factors on the anthropometric status of children. Skoufias and Vinha (2012) analysed the impact of the weather on child height in rural Mexico from 1951 to 1985 and found that after positive rainfall shocks, defined as one or two standard deviations more than the average 1951-1985 rainfall, children were shorter regardless of their location or altitude. Negative temperature shocks, defined as one or two standard deviations less than the average 1951-1985 tempera-
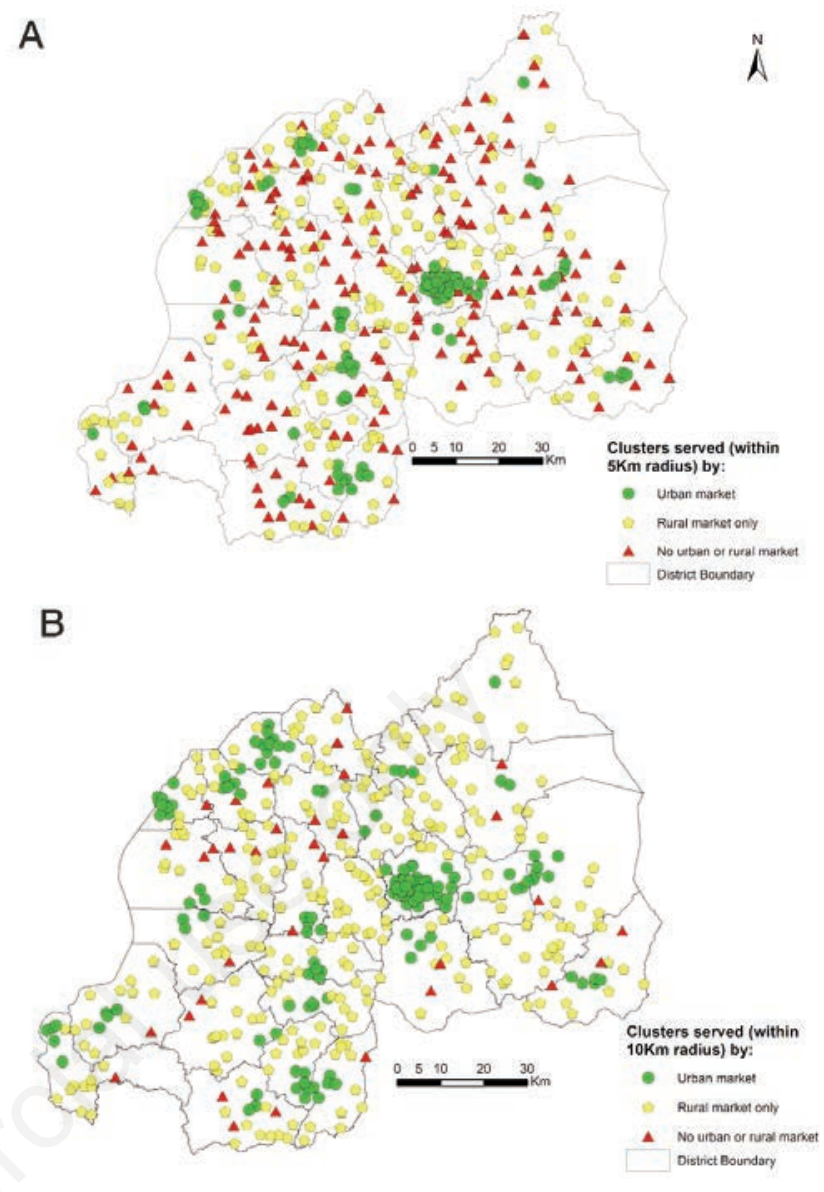

Figure 5. Distribution of household clusters as served by the three categories of markets. A) Within a 5-km distance; and B) a 10-km distance.

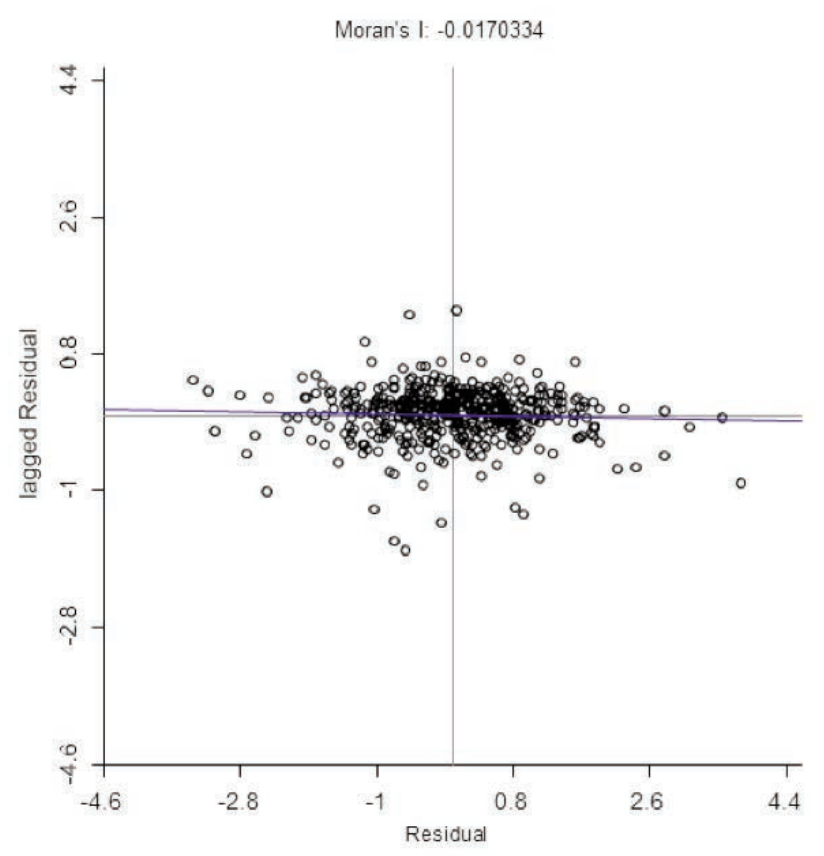

Figure 6. Moran's I for the residuals. 
ture, also had a negative impact on child's height but only for high altitude areas (Skoufias and Vinha, 2012).

Household clusters that were served by rural markets had a significant negative association with height-for-age compared to clusters that were served by urban markets. This association had the second highest effect on the height-for-age of children after the children's birth weight. This result supports our hypothesis that households that obtain food supplies from markets at the lower end of the food supply chain have a higher risk of aflatoxin exposure. Given that these findings are based on a proxy only, this finding should be treated with caution. Also, in reality, the dynamics of aflatoxin production along the food supply are complex which means that our hypothesis requires further validation by studying the occurrence of this toxin along the food supply chain and quantifying contamination levels. On the other hand, due to the lack of explicit national spatial data on aflatoxins in foods, which is the case in many developing countries, our approach could be applied in other research settings on mycotoxins. Our study revealed that the identified variability in stunting prevalence at the cluster level is lost when stunting levels are aggregated to the district level. This can have considerable implications for stunting reduction policies because a district might be classified as having low stunting and thus not be given priority for programme intervention even if high stunting prevalence could exist at the sub-district or cluster level. To enable more geographically targeted policies and programmes in future, it is important to consider cluster-level variations in stunting prevalence.

The use of the Rwanda DHS 2014-15 data had several strengths and the consideration of biophysical factors and a proxy measure of the exposure to aflatoxins in addition to socio-economic factors rendered the analysis more robust, enabling spatially explicit predictions of stunting occurrence. First, we analysed both child and mother characteristics, further increasing the robustness of the analysis. Second, the DHS survey provided a range of explanatory variables of good quality data. Third, the availability of spatial data enabled us to analyse biophysical factors associated with stunting at the household cluster-level which, to the best of our knowledge, has not been done before in Rwanda. Using the household clusters, we could take into account the spatial variability of the covariates, visualise the spatial distribution of height-forage at a fine-scale resolution, control for spatial autocorrelation, and finally make a spatial prediction map for height-for-age. Our

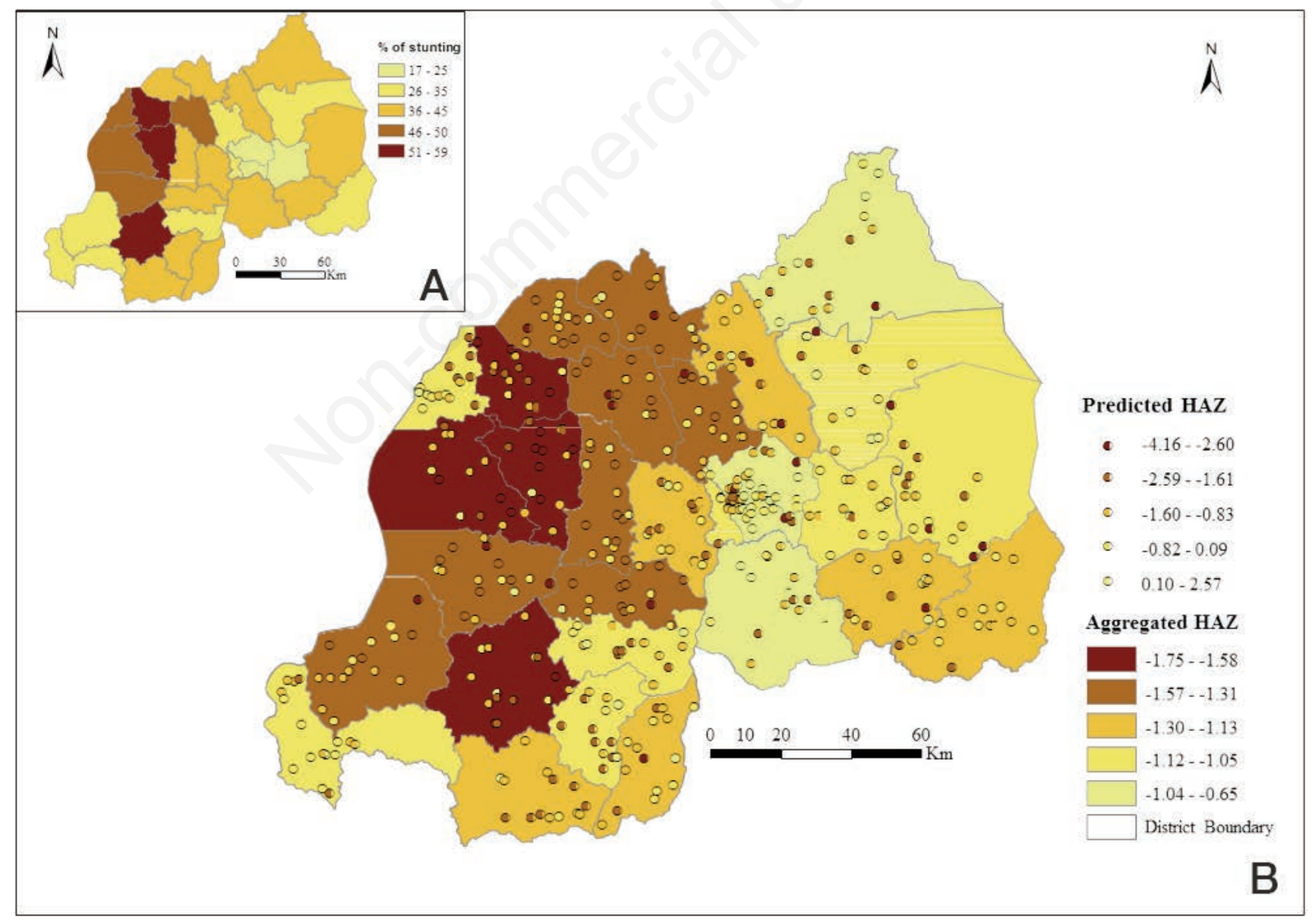

Figure 7. Model-predicted height-for-age z-scores (HAZ) per cluster. Based on Demographic and Health Survey, 2015. A) Per district and $B$ ) with the same values shown in the background aggregated at the district level compared to the prevalence of stunting. 
study also had limitations. Although for the extraction of environmental factors and the estimation of household exposure to aflatoxins the displacement of the household clusters was taken into account; there will be a margin of error as the true locations of the clusters remain unknown (Burgert et al., 2013). Also, our proxy for aflatoxins exposure via the food supply chain requires further evidence. This is because of the complex interplay of factors leading to aflatoxins produced in food products (Sanchis and Magan, 2004; Sakisaka et al., 2006). Also, our scenario considered only the hierarchy of markets as the source of exposure, which does not take into account the exposure experienced by households that produce and store maize for their own consumption.

\section{Conclusions}

Our study confirms not only the usual effect of child and mother factors on height-for-age but also shows the influence of environmental factors in determining the height-of-age of children in Rwanda. Elevation and being supplied by markets at the lower end of the food supply chain were found to be significantly associated with low height-for-age. Thus, an understanding and consideration of the environmental drivers of stunting is crucial in order to produce a holistic approach in addressing low height-for-age in children under five years. Our use of household clusters shows the variability of stunting across the study area. In most published studies, the analysis is generally conducted at the household level with no spatial component considered. Although this approach provides valuable insights into the determinants of stunting on individual and household levels, most governmental interventions are targeted at the regional scale. Future research should focus on studying in depth the clustering observed in the height-for-age measure, to better understand the individual determinants of stunting at a finer scale. Conducting such a research could shed light on overlooked, yet determining correlates of stunting, which would result in better geographically targeted interventions and prioritisation of areas affected. It would also contribute to an examination of the temporal change in hotspots of stunting during the past years, which would lead to a better understanding of the spatial variation in the distribution of stunting. For Africa and Rwanda specifically, there is a need for more interdisciplinary research, incorporating geographical information system applications in understanding the complexity of stunting, to complement the research usually conducted on an individual or household level in the nutrition or social science fields. Finally, there is a tremendous data gap to be filled on the extent of mycotoxin exposure on the national level and how this affects linear growth, not only at the individual level but also at a regional and national scale.

\section{References}

Amuzie C, Bandyopadhyay R, Bhat RV, Black R, Burger H, Cardwell KF, Gelderblom W, Gong YY, Groopman JD, Kimanya M, Miller JD, Oswald I, Pascale M, Payne GA, Phillips TD, Riley R, Shephard GS, Stoltzfus R, SugitaKonishi Y, Turner PC, Wogan GN, Wu F, 2016. Mycotoxin control in low- and middle-income countries. Wild CP, Miller D, Groopman JD, Lyon, France.

AUC, NEPAD, 2013. The cost of hunger in Rwanda, social and economic impacts of child undernutrition in Rwanda, implications on national development and vision 2020. African Union Commission (ACU), NEPAD Planning and Coordinating Agency, Economic Commission for Africa (ECA), World Food Programme (WFP), Rwanda.

Binagwaho A, Farmer PE, Nsanzimana S, Karema C, Gasana M, de Dieu Ngirabega J, Ngabo F, Wagner CM, Nutt CT, Nyatanyi T, Gatera M, Kayiteshonga Y, Mugeni C, Mugwaneza P, Shema J, Uwaliraye P, Gaju E, Muhimpundu MA, Dushime T, Senyana F, Mazarati JB, Gaju CM, Tuyisenge L, Mutabazi V, Kyamanywa P, Rusanganwa V, Nyemazi JP, Umutoni A, Kankindi I, Ntizimira C, Ruton H, Mugume N, Nkunda D, Ndenga E, Mubiligi JM, Kakoma JB, Karita E, Sekabaraga C, Rusingiza E, Rich ML, Mukherjee JS, Rhatigan J, Cancedda C, Bertrand-Farmer D, Bukhman G, Stulac SN, Tapela NM, van der Hoof Holstein C, Shulman LN, Habinshuti A, Bonds MH, Wilkes MS, Lu C, Smith-Fawzi MC, Swain JD, Murphy MP, Ricks A, Kerry VB, Bush BP, Siegler RW, Stern CS, Sliney A, Nuthulaganti T, Karangwa I, Pegurri E, Dahl O, Drobac PC, 2014. Rwanda 20 years on: investing in life. Lancet 384:371-5.

Black RE, Allen LH, Bhutta ZA, Caulfield LE, de Onis M, Ezzati M, Mathers C, Rivera J, Maternal, Child Undernutrition Study G, 2008. Maternal and child undernutrition: global and regional exposures and health consequences. Lancet 371:243-60.

Black RE, Victora CG, Walker SP, Bhutta ZA, Christian P, de Onis M, Ezzati M, Grantham-McGregor S, Katz J, Martorell R, Uauy R, Maternal, Child Nutrition Study G, 2013. Maternal and child undernutrition and overweight in low-income and middle-income countries. Lancet 382:427-51.

Burgert CR, Colston J, Roy T, Zachary B, 2013. Geographic displacement procedure and georeferenced data release policy for the Demographic and Health Surveys. DHS Spatial Analysis Reports No. 7. ICF International, Calverton, Maryland, USA.

Chopra M, 2003. Risk factors for undernutrition of young children in a rural area of South Africa. Public Health Nutr 6:645-52.

Condo JU, Gage A, Mock N, Rice J, Greiner T, 2015. Sex differences in nutritional status of HIV-exposed children in Rwanda: a longitudinal study. Trop Med Int Health 20:17-23.

Cotty PJ, Jaime-Garcia R, 2007. Influences of climate on aflatoxin producing fungi and aflatoxin contamination. Int $\mathrm{J}$ Food Microbiol 119:109-15.

Dang S, Yan H, Yamamoto S, Wang X, Zeng L, 2004. Poor nutritional status of younger Tibetan children living at high altitudes. Eur J Clin Nutr 58:938-46.

de Onis M, Borghi E, Arimond M, Webb P, Croft T, Saha K, DeRegil LM, Thuita F, Heidkamp R, Krasevec J, Hayashi C, Flores-Ayala R, 2019. Prevalence thresholds for wasting, overweight and stunting in children under 5 years. Public Health Nutr 22:175-9.

de Onis M, Branca F, 2016. Childhood stunting: a global perspective. Matern Child Nutr 12:12-26.

de Sherbinin A, 2011. The biophysical and geographical correlates of child malnutrition in Africa. Popul Space Place 17:27-46.

Dewey KG, Begum K, 2011. Long-term consequences of stunting in early life. Matern Child Nutr 7:5-18.

Dewey KG, Huffman SL, 2009. Maternal, infant, and young child nutrition: combining efforts to maximize impacts on child growth and micronutrient status. Food Nutr Bull 30:S187-9.

FAO, IFAD, UNICEF, WHFP, WHO, 2017. The State of Food Security and Nutrition in the World 2017. Building resilience 
for peace and food security. FAO, Rome, Italy.

Gbashi S, Madala NE, Adekoya I, Adebo O, De Saeger S, De Boevre M, Njobeh PB, 2018. The socio-economic impact of mycotoxin contamination in Africa. In Njobeh PB, ed. Fungi and mycotoxins - their occurrence, impact on health and the economy as well as pre- and postharvest management strategies. Available from: https:/www.intechopen.com/books/ mycotoxins-impact-and-management-strategies/the-socioeconomic-impact-of-mycotoxin-contamination-in-africa

Hell K, Mutegi C, 2011. Aflatoxin control and prevention strategies in key crops of Sub-Saharan Africa. Afr J Microbiol Res 5:459-66.

INSR, Macro O, 2006. Rwanda Demographic and Health Survey 2005. Institut National de la Statistique du Rwanda (INSR), ORC Macro, Calverton, Maryland, USA.

Kamika I, Ngbolua KTN, Tekere M, 2016. Occurrence of aflatoxin contamination in maize throughout the supply chain in the Democratic Republic of Congo. Food Control 69:292-6.

Khlangwiset P, Shephard GS, Wu F, 2011. Aflatoxins and growth impairment: a review. Crit Rev Toxicol 41:740-55.

Lu C, Mejia-Guevara I, Hill K, Farmer P, Subramanian SV, Binagwaho A, 2016. Community-based health financing and child stunting in rural Rwanda. Am J Public Health 106:49-55.

Mendelsohn J, Jarvis A, Robertson T, Nyiratuza M, 2016. Rwanda: the measure of a land. Vital Signs, Kigali, Rwanda.

MIGEPROF, 2018. Rwanda Country Strategic Review of Food and Nutrition Security. Ministry of Gender and Family Promotion, Kigali, Rwanda.

MINAGRI, NISR, WFP, 2016. Rwanda 2015-Comprehensive food security and vulnerability analysis. MINAGRI, NISR, WFP, Kigali, Rwanda.

MINALOC, MOH, MINAGRI, 2014. National Food and Nutrition Strategic Plan 2013-2018. MINALOC, MOH, MINAGRI, Rwanda.

Nikoi E, Anthamatten P, 2013. An examination of environmental correlates with childhood height-for-age in Ghana. Public Health Nutr 16:46-53.

NISR, MINECOFIN, 2012. Fourth Rwanda Population and Housing Census (2012 RPHC) Census Atlas. National Institute of Statistics, Ministry of Finance and Economic Planning, Rwanda.

NISR, MOH, ICF, 2010. Rwanda Demographic and Health Survey 2010. National Institute of Statistics of Rwanda (NISR), Ministry of Health (MOH), ICF International, Calverton, Maryland, USA.

NISR, MOH, ICF, 2015. Rwanda Demographic and Health Survey 2014-15. National Institute of Statistics of Rwanda (NISR), Ministry of Health (MOH), ICF International, Rockville, Maryland, USA.

Nyandwi E, Veldkamp T, Amer S, 2016. Regional climate sensitivity of wetland environments in Rwanda: the need for a location-specific approach. Reg Environ Change 16:1635-47.
Onis M, 2007. WHO Child Growth Standards based on length/height, weight and age. Acta Paediatr 95:76-85.

Pitt JI, 2000. Toxigenic fungi and mycotoxins. Br Med Bull 56:184-92.

Rutstein SO, Rojas G, 2006. Guide to DHS Statistics Demographic and Health Surveys Methodology. Measure DHS/ICF International, Calverton, Maryland, USA.

Sakisaka K, Wakai S, Kuroiwa C, Flores LC, Kai I, Mercedes Arago'n M, Hanada K, 2006. Nutritional status and associated factors in children aged 0-23 months in Granada, Nicaragua. Public Health 120:400-11.

Sanchis V, Magan N, 2004. 8 - Environmental conditions affecting mycotoxins. In: Magan N, Olsen M, eds. Mycotoxins in food. Woodhead Publishing, Cambridge, UK. pp 174-189.

Shephard GS, 2008. Impact of mycotoxins on human health in developing countries. Food Addit Contam Part A Chem Anal Control Expo Risk Assess 25:146-51.

Skoufias E, Vinha K, 2012. Climate variability and child height in rural Mexico. Econ Hum Biol 10:54-73.

Stewart CP, Iannotti L, Dewey KG, Michaelsen KF, Onyango AW, 2013. Contextualising complementary feeding in a broader framework for stunting prevention. Matern Child Nutr 9:2745.

Udomkun P, Wiredu AN, Nagle M, Bandyopadhyay R, Muller J, Vanlauwe B, 2017. Mycotoxins in Sub-Saharan Africa: Present situation, socio-economic impact, awareness, and outlook. Food Control 72:110-22.

Uwiringiyimana V, Ocke MC, Amer S, Veldkamp A, 2018. Predictors of stunting with particular focus on complementary feeding practices: A cross-sectional study in the northern province of Rwanda. Nutrition 60:11-8.

Victora CG, Adair L, Fall C, Hallal PC, Martorell R, Richter L, Sachdev HS, Maternal, Child Undernutrition Study G, 2008. Maternal and child undernutrition: consequences for adult health and human capital. Lancet 371:340-57.

Victora CG, de Onis M, Hallal PC, Blossner M, Shrimpton R, 2010. Worldwide timing of growth faltering: revisiting implications for interventions. Pediatrics 125:e473-80.

Vilcins D, Sly PD, Jagals P, 2018. Environmental risk factors associated with child stunting: a systematic review of the literature. Ann Global Health 84:551.

Voss PR, Long DD, Hammer RB, Friedman S, 2006. County child poverty rates in the US: a spatial regression approach. Popul Res Policy Rev 25:369-91.

Wamani H, Åstrøm AN, Peterson S, Tumwine JK, Tylleskär T, 2007. Predictors of poor anthropometric status among children under 2 years of age in rural Uganda. Public Health Nutr 9:320-6.

Wild CP, Gong YY, 2010. Mycotoxins and human disease: a largely ignored global health issue. Carcinogenesis 31:71-82. 